Avaiable online at www.banglajol.info

Bangladesh J. Sci. Ind. Res. 43(3), 333-344, 2008
BANGLADESH JOURNAL OF SCIENTIFIC AND INDUSTRIAL RESEARCH

E-mail: bjsir07gmail.com

\title{
Acid Cleaning Operation for Scale Attacked Water Wall Tubes of a High Pressure Boiler
}

\author{
M. Azad Sohail*a and A. Ismail Mustafab \\ ${ }^{a}$ Central Chemical Research Laboratory, Ghorasal Thermal Power Station, BPDB, Palash, \\ Narsingdi-1610 and bepartment of Applied Chemistry \& Chemical Technology, \\ University of Dhaka,Dhaka-1000,Bangladesh
}

\begin{abstract}
In this paper, a two stage acid etching (TSAE) technique has been developed and investigated to cleanup hard deposits on internal surfaces of boiler water wall tubes (WWTs) for a natural circulation highpressure drum boiler(fossil) unit: TIME-206-COB (Russia) at Ghorasal Thermal Power Station(GTPS), Bangladesh. TSAE technique was carried out very carefully by using a mixed solution of ammonium hydrogen fluoride, hydrochloric acid in presence of inhibitor urotropine and cleaning agent OP10(Russia).To attained maximum cleaning efficiency at each end of the cleaning stage compressed air $6 \mathrm{~kg}_{\mathrm{f}} \mathrm{cm}^{-2}$ was passed through the boiler WWTs by bottom headers very carefully. The overall close observations on the (TSAE)) cleaning operation revealed that not less than $90 \%$ of impurities were removed. The cleaning mechanism and the passivation on cleaned surface of boiler WWTs by $2.0 \%$ $\mathrm{NaNO}_{3}$ in presence of $0.5 \% \mathrm{NH}_{4} \mathrm{OH}(\mathrm{pH} 10.5)$ at $55^{\circ} \mathrm{C}$ were found to be satisfactory. Close macrostructural examinations (by SEM) of the tube materials after the TSAE operations reveled there is no remarkable corrosion or micro creaks on boiler WWTs materials.
\end{abstract}

Key words: Boiler, Deposit, Passivation, Boiler water wall tubes (WWTs), Acid etching.

\section{Introduction}

Water wall tubes (WWTs) are the most effective heat gaining components for a natural circulation high -pressure drum boilers. Scale formation in internal surface of boiler WWTs is one of the major problems in most of the high-pressure boilers of thermal power stations. When water is heated under pressure and concentrated by evaporation, as in a steam boiler, some of the dissolved mineral matter goes out of solution and deposited, either as a hard scale or as a soft sludge, depending on the characteristics of the water. There are various factors which cause the formation of deposit on internal heating sur-

*Corresponding author: E-mail: masohail2004@yahoo.com 
faces viz, water borne minerals, treatment chemicals, corrosion product (pre-boiler and boiler), and contaminants. Deposits from these sources may interact to increase deposition rates, produce a more tenacious layer, and which decreases boiler efficiently and ultimately causes in boiler failure. Zhaoying (1999) employed glycolic acid and formic acid for the cleaning of corroded power plant boiler made with austenitic steel. Zhao (1999) used alkali for cleaning of small size boilers. Bodong and Changzheng (1999) investigated the cleaning efficiency of citric acid for cleaning of power plant boiler, while Changzheng et al (1999) designed a cleaning system for a sub critical pressure boiler using hydrochloric acid and passivated with nitrate solution. Changming(2000), Sakurai et al. (2000), Poulson and Robision (1980), French (1981), Sohail et al. (1997, 2001, 2002, 2006) investigated and developed different techniques for boiler chemical cleaning.

The WWTs of a natural circulation highpressure (158 $\left.\mathrm{Kg}_{\mathrm{f}} \cdot \mathrm{cm}^{-2}\right)$ drum boiler unit(TIME -206-COB, Russia, electric generation capacity 210 MW)of Ghorasal Thermal Power Station ,GTPS, unit No. 4, Bangladesh were attacked by undesired hard deposits. The fossil (gas) based boiler was not chemically cleaned for the last twelve years (approximately 96000h) of operation. During overhauling hard deposits was observed on inside surfaces of boiler WWTs. Therefore it becomes an important task to clean-up the deposits. Prior to cleaning operation a close investigation was carried out to characterize the deposits, so that a new boiler acid cleaning technique can be developed. On the basis of characteristics of the deposits a two stage acid etching (TSAE ) technique has been developed and employed to clean up the deposits on internal surfaces of boiler WWTs . In this cleaning technique ammonium hydrogen fluoride mixed with hydrochloric acid was employed instead of hydrofluoric acid due to its easy handling as well as safe transportations. During passivation of the boiler unit a mixed solution of sodium nitrate with ammonium hydroxide were used as a passivating agent. Each of the acid etching stage inhibitor urotropine was applied properly to avoid any types of corrosion on metal surfaces.

\section{Materials and Methods}

The boiler WWTs to be clean up was a natural circulation water wall tubes high-pressure $\left(158 \mathrm{Kg}_{\mathrm{f}} \cdot \mathrm{cm}^{-2}\right)$ drum boiler unit: TIME206-COB (Russia) .The boiler having electric and steam generating capacities are 210 MW and 670T h-1 respectively. Before TSAE operation the bottom headers of boiler WWTs were connected with two dosing pumps (each of capacity $40 \mathrm{~m}^{3} \mathrm{~h}^{-1}$ ) followed by cleaning solution dosing tank (boiler drainage tank) by temporary setup pipes lines (Fig. 1). The inner pipelines of the boiler drum were blocked by wooden plugs. Dosing of cleaning chemicals into the boiler WWTs was made very carefully up to 


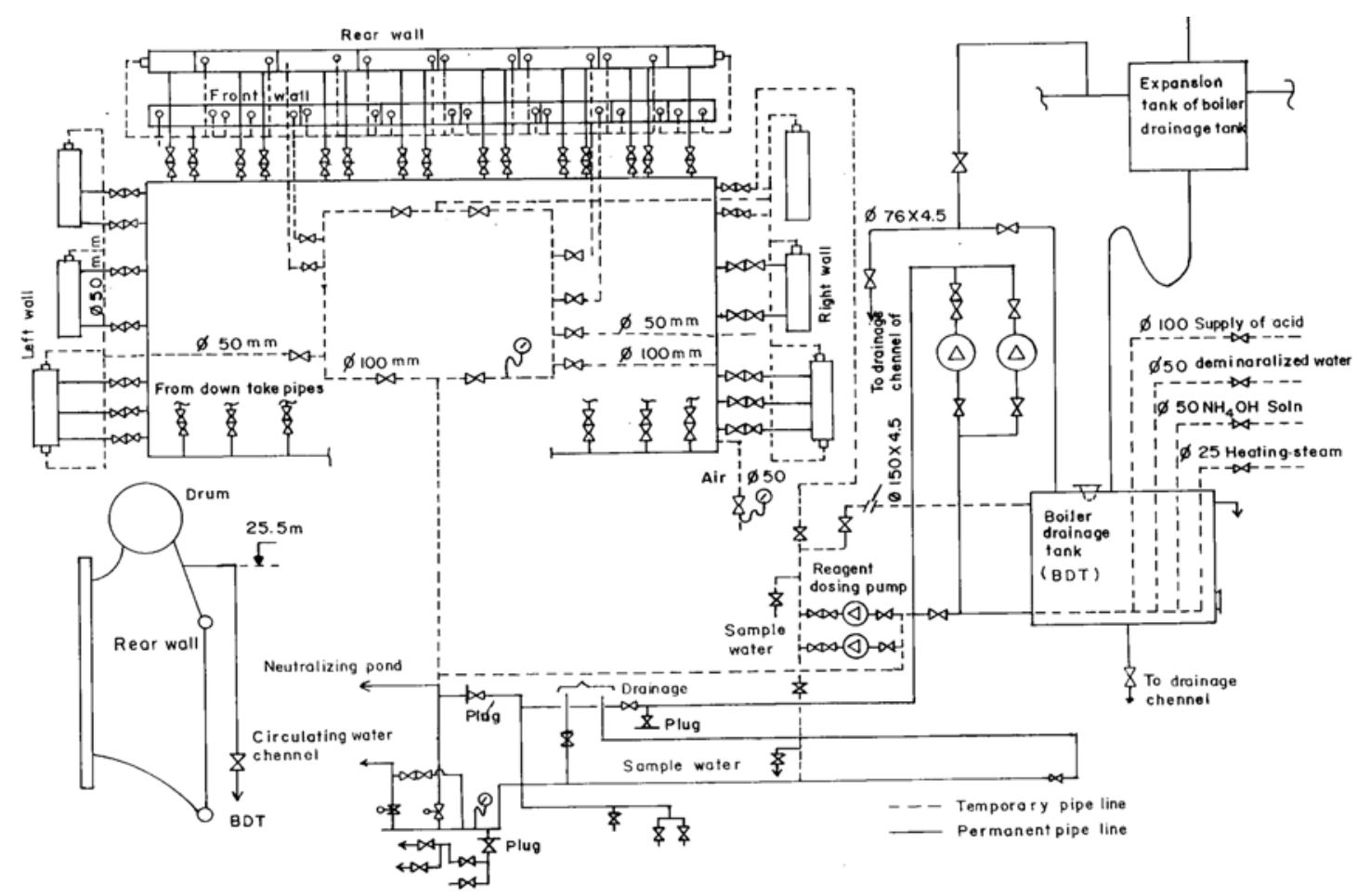

Fig. 1. Cleaning solution producing and drainage lines used for acid cleaning of water wall tubes(WWTs) for a natural circulation high-pressure boiler. Doted lines indicate the temporary pipe lines.

pumps through the bottom headers. Each end of the cleaning stage the washing chemicals were drained off from the boiler WWTs to a neutralizing pond by temporary installed auxiliary drain lines. The schematic set up for acid cleaning operation is shown in Fig. 1.

\section{Cleaning chemicals and reagents}

Chemicals used for analyses were of analytical grade, procured from BDH (England) and E. Merck (Germany). Chemicals used for cleaning operation were hydrazine hydrate 32\% (France), urotropine (hexamethyline tetra amine) 99.5\% (Russia), sodi um nitrate $\left(\mathrm{NaNO}_{3}\right)$ 98.6\% (Russia), OP-10 (Russia), ammonium hydrogen fluoride $\left(\mathrm{NH}_{4} \mathrm{HF}_{2}\right)$ 99.55\% (Russia), hydrochloric acid 32\% (BCIC, Bangladesh), and compressed ammonia gas (BCIC, Bangladesh).

\section{Instruments}

The analyses of iron and copper ions (Jeffery et al.1987 and Operation Manual GTPS,1973) were carried out with an Atomic Absorption Spectrophotometer (AAS, Model: AA6650, Shimadzu, Japan) and while analyses phosphate, hydrazine, ammonia, nitrate and silicate were 
made(Kostrikin, 1967, Operation Manual, GTPS, 1973 and Jeffery et al. 1987) by photoelectric colorimeter(Model: KFK-2 ,Russia). pH and ionic strengths were measured with a pH and Ion meter( digital Model: 130.04.1 ,Russia). Conductivity meter (digital Model: Bibby, England), Oven (Model: N-08. 76, Russia) and Furnace (Model: Mn2YM, Russia) were also used during this work.

\section{Analyses of deposits}

Compositions of deposits (as oxide) were determined by gravimetric (Kostrikin, 1967) followed by titrimetric (Operation manual, 1973) and colorimetric analyses (Jeffery et al. 1989). For each case multiple analyses were made and their average values are represented in Table I and Table II respectively. The initial quantity of deposits attained in boiler WWTs, before cleaning operation were determined (Table III) by rubbing out of $\left(3 \times 3 \mathrm{~cm}^{2}\right)$ area of deposit from weighed sample and expressed in g.m-2. Concentrations (mg L-1) of ionic impurities removed in chemical solution at different stages (Table IV) of boiler cleaning operation were measured by AAS (iron, copper) and colorimetric (silicate, phosphate) analyses. The residual quantities followed by qualities of deposits remained in boiler WWTs after cleaning operation are given in Table V and Table VI respectively.

\section{Cleaning procedure}

\section{Hydraulic test for boiler}

After completion of overhauling of the power plant unit No. 4 at GTPS, the boiler unit was prepared for acid cleaning operation (Fig. 1).The boiler drainage tank (BDT) was used for the preparation of the cleaning solution. The BDT was connected with the boiler WWTs by two dosing pumps by temporary pipe lines (doted lines). To confirm the tightness of boiler unit hydraulic test was carried out using demineralized water at a flow rate of $90( \pm 5) \mathrm{m}^{3} \mathrm{~h}^{-1}$ (pressure 8

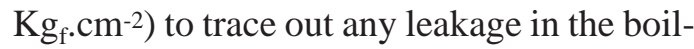
er system.

\section{Two-stage acid etching (TSAE) technique}

TSAE followed by passivation operations were carried out for clean-up deposits from boiler WWTs (carbon steel, st.-20, Russia) for a natural circulation WWTs high-pressure drum boiler (TIME- 206- COB,Russia) unit No. 4 at Ghorasal Thermal Power Station (GTPS), Bangladesh. The chemical composition of boiler WWTs materials (carbon steel, st.-20, Russia) is C $0.22 \%$, $\mathrm{Si}$ $0.2 \%$, Mn $0.42 \%$, S $0.02 \%$ and P 0.0 1\% respectively. The cleaning area extended up to $25.5 \mathrm{~m}$ height (just below the drum) of boiler WWTs, containing $60 \mathrm{~m}^{3}$ of inside volume with $140 \mathrm{~m}^{2}$ of surface area. In this cleaning process the removal of copper impurities was not taken into the consideration, because of very low ( $0.22 \%)$ of copper 
(as $\mathrm{CuO}$ ) observed in the deposit. The traces of copper impurities were removed by acid solution during TSAE operation. For the removal of silicates from the boiler deposits ammonium hydrogen fluoride was employed instead of hydro fluoric acid in order to find out its cleaning efficiency, as well as of its safe handling and transportation. However, hydrochloric acid and inhibitors were also employed in each stages of acid etching.

\section{(i) Super-heater passivation (SHP)}

The super-heaters(alloy steel, Russia) of the boiler were first filled with hydrazine (l mgL-1 ) followed by ammonia solution till $\mathrm{pH} 10.5$ was attained and then all the six water wall panel groups of the boiler were washed stage wise with demineralized water (at $\left.100^{\circ} \mathrm{C}\right)$ at a flow rate of $60( \pm 10) \mathrm{m}^{3 \mathrm{~h}}{ }^{-1}$.

\section{(ii) First stage acid etching (FSAE)}

Prior to cleanup deposits from boiler WWTs, $60 \mathrm{~m}^{3}$ of cleaning solution containing $0.6 \%$ $\mathrm{HF}$ (using ammonium hydrogen fluoride $\mathrm{NH}_{4} \mathrm{HF}_{2}$ ), 6\% HCI, 0.45\% urotropine and $1 \%$ OP-10 (cleaning and foaming agent)at $60 \mathrm{O}( \pm 5)^{\circ} \mathrm{C}$ was prepared and introduced into the boiler WWTs ( up to height $25.5 \mathrm{~m}$ ) carefully through bottom headers using the dosing pumps(as Fig. 1). The cleaning solution was kept in the tubes for $10 \mathrm{~h}$ and then drained out. It should be mentioned that, for each acid cleaning stage compressed air (6 $\mathrm{Kg.} .^{-2}$ ) was applied ( by a narrow tube through bottom headers) at the end to facilitate the mixing of cleaning solution in
WWTs and to increase the efficiency of the process. The concentrations of different impurities removed during cleaning operation were analyzed cautiously from the waste cleaning effluents and their average values are presented in Table IV. After completion of FSAE, the WWTs were washed with demineralized water at $90^{\circ}( \pm 5)$ oC with a flow rate of $100 \mathrm{~m}^{3} \mathrm{~h}^{-1}$ for $2 \mathrm{~h}$..

\section{(iii) Second stage acid etching (SSAE)}

At this stage $60 \mathrm{~m}^{3}$ of cleaning solution containing $0.5 \%$ urotropine, $0.5 \% \mathrm{HF}$ (using ammonium hydrogen fluoride $\mathrm{NH}_{4} \mathrm{HF}_{2}$ ), $5.5 \% \mathrm{HCl} 1 \%$ OP-10 (cleaning and foaming agent $)$ at $65^{\circ}( \pm 5)^{\circ} \mathrm{C}$ was introduced into the boiler WWTs ( up to height $25.5 \mathrm{~m}$ ) through bottom headers using dosing pumps. The solution was kept inside for $12 \mathrm{~h}$ at $60^{\circ}( \pm 5)$ oC. Compressed air (6 Kg.cm-2)was applied (by narrow tube through bottom headers) at the end to facilitate the mixing of cleaning solution in WWTs and to increase the efficiency of the process. After completion of the cleaning operation the cleaning effluents were drained off and washout as procedure mentioned in FSAE. The concentration of impurities quitted in the cleaning solution was determined accurately (Table IV).

\section{(iv) Neutralization of residual acid}

The step was carried out very carefully to neutralizing the acid remained on the surfaces of the tube walls materials after acid cleaning (FSAE and SSAE) operation. Because residual acid remained may cause in hydrogen damage during start up of the unit. 
The residual acid was neutralized by dosing $1 \%$ ammonia hydroxide $\left(\mathrm{NH}_{4} \mathrm{OH}\right)$ at $50^{\circ} \mathrm{C}$ into the boiler WWTs and kept it for $4 \mathrm{~h}$ and drained out (approximately $\mathrm{pH} 10$ ) into the neutralizing pond.

(v) Passivation of the cleaned surfaces (PCS)

After cleaning operation, the surfaces of the materials remained in an activated state. Therefore passivation is quick necessary to resist any types of corrosion. Passivation of the boiler WWTs cleaned surfaces was done by dosing a solution containing $2 \% \mathrm{NaNO}_{3}$ and $0.5 \% \mathrm{NH}_{4} \mathrm{OH}\left(\mathrm{pH} \mathrm{10.5)}\right.$ at $55{ }^{\circ} \mathrm{C}$ in the boiler WWTs and kept it for $5 \mathrm{~h}$ and drained out into the neutralizing pond. After completion of TSAE followed by passivation, the manholes of boiler bottom water walls headers were opened for the internal inspection.

\section{Results and Discussion}

The water wall tubes (WWTs) of the natural circulation high-pressure (158 Kg.cm-2) drum boiler unit :TIME-206-COB (Russia) at Ghorasal Thermal Power Plant (GTPS), Bangladesh was attacked by deposits. During overhauling of the mentioned power station (after $96000 \mathrm{~h}$ of operation ), careful inspection revealed gray colored, irregular, tenacious, hard deposits on the inside surfaces of boiler WWTs (carbon steel,st.20,Russia). Close analyses of the deposits (as oxide) depicted that it contained maximum amount (average) of $\mathrm{Fe}_{2} \mathrm{O}_{3}(63.2 \%)$ followed by $\mathrm{SiO}_{2}(12.7 \%), \mathrm{CaO}(9.34 \%), \mathrm{P}_{2} \mathrm{O}_{5}$ (4.38\%), $\mathrm{MgO}(5.84 \%), \mathrm{Al}_{2} \mathrm{O}_{3}$ (3.8\%) and $\mathrm{CuO}(0.21 \%)$ respectively( Table I and Table II). The highest amount $\left(488 \mathrm{gm}^{-2}\right)$ of deposits

Table I. Composition (\%) of deposits at different location of boiler WWTs before cleaning operation

\begin{tabular}{l|c|c|c|c|c|c|c}
\hline Identity of tubes & \multicolumn{7}{|c}{ Composition (\%) } \\
\hline & $\mathrm{Fe}_{2} \mathrm{O}_{3}$ & $\mathrm{SiO}_{2}$ & $\mathrm{Al}_{2} \mathrm{O}_{3}$ & $\mathrm{CaO}$ & $\mathrm{MgO}$ & $\mathrm{P}_{2} \mathrm{O}_{5}$ & $\mathrm{CuO}$ \\
Front wall *P-3, T-11 & 64.1 & 12.3 & 3.1 & 9.3 & 4.2 & 5.8 & 0.22 \\
Back wall P-1, T-12 & 64.2 & 12.6 & 2.7 & 9.8 & 4.9 & 4.0 & 0.21 \\
Front wall P-3, T-6 & 65.1 & 10.3 & 3.1 & 9.0 & 5.4 & 4.7 & 0.18 \\
Back wall P-2, T-11 & 65.2 & 12.48 & 3.6 & 9.2 & 4.1 & 4.4 & 0.17 \\
*P - Panel, *T - Tube & & & & & & & \\
\hline
\end{tabular}

Table II. Average composition of mixed deposits from different tubes before cleaning operation.

\begin{tabular}{l|c|c|c|c|c|l|l}
\hline Constituents & $\mathrm{Fe}_{2} \mathrm{O}_{3}$ & $\mathrm{SiO}_{2}$ & $\mathrm{Al}_{2} \mathrm{O}_{3}$ & $\mathrm{CaO}$ & $\mathrm{MgO}$ & $\mathrm{P}_{2} \mathrm{O}_{5}$ & $\mathrm{CuO}$ \\
Average (\%) & 63.2 & 12.7 & 3.8 & 9.34 & 5.84 & 4.38 & 0.21 \\
\hline
\end{tabular}


was observed in boiler WWTs fire side (TabIe III) after $96000 \mathrm{~h}$ of plant operation. The value exceeds the Japanese cleaning limit $400 \mathrm{gm}^{-2}$ (Chemistry control of thermal power plant training materials,1987 )but slight lower than that of the Russian cleaning limit $500 \mathrm{gm}^{-2}$ (Kostrikin,1967).

Deposit stratification in boiler WWTs indicates changes in operating boiler water cycle chemistry as well as long time remain at high temperature. However, the formation of deposits in such a type of natural circulation WWTs high pressure boiler unit might be due to contamination of feed water, leakage of cooling raw water into turbine condensate, low softening or contamination of make up water, local high rate of heat flow through steam generating tubes, weak circulation of steam water system, low or high dose of necessary reagents into the boiler chemical water regime (WCR), non-uniform boiler blow-down (periodical or continuous), administration of wrong prescribed parameters for boiler WCR and operational fault. On the basis of extensive laboratory (deposit dissolution) analyses, the TSAE has been designed and employed to clean-up undesired impurities on boiler WWTs. Extensive pre-laboratory analyses revealed more than $70 \%$ impurities can be removed in the first stage of cleaning process (kept $10 \mathrm{~h}$ ). And remaining 30\% impurities can be removed by employing next same concentration of cleaning solution (kept 10 h). Usually silicates remain in boiler deposits at various compositions. The analysis revealed that the deposit of WWTs contains comparatively large quantities of $\mathrm{SiO}_{2}$ (10.3-12.6\%) (Table II). Therefore to remove silicate from boiler WWTs ammonium hydrogen fluoride was used instead of hydrofluoric acid, which produces hydro fluoric acid (HF) in presence of water and capable to dissolves silicates remained in the deposit. Deposit analyses results also depicted (Table I and Table II) that deposits contained lower quantity (maximum $0.22 \%$ as $\mathrm{CuO}$ ) of copper in its constituent. Therefore, copper removal step was not employed in the cleaning operation. The residual quantity of deposits was with drawn by the acidic solution in presence of urotropine .lf deposit contained more copper in it's constitute then first thio-urea or potassium per-sulfate cleaning is essential for the removal of copper content. Otherwise copper is first dissolving from the deposit and then it may settled down on the boiler tubes surfaces by reacting with ferric ions.

$\mathrm{NH}_{4} \mathrm{HF}_{2}+2 \mathrm{H}_{2} \mathrm{O}=2 \mathrm{HF}+\mathrm{NH}_{4} \mathrm{OH}$

$12 \mathrm{HF}+3 \mathrm{SiO}_{2}=2 \mathrm{H}_{2} \mathrm{SiF}_{6}+\mathrm{H}_{4} \mathrm{SiO}_{4}+2 \mathrm{H}_{2} \ldots$ (2)

Silicates in the deposit was removed (Table IV) by charging $0.6 \% \mathrm{HF}$ (using $\mathrm{NH}_{4} \mathrm{HF}_{2}$ mixed with hydrochloric acid, urotropine) into the WWTs (as mentioned in experimental procedure) and holding the same in the tubes for $10 \mathrm{~h}$ and then drained out. The process was repeated for the second time for better cleaning (keeping time $10 \mathrm{~h}$ ) as per laboratory test. So the cleaning process is 
called two stage acid etching (TSAE).

$\mathrm{SiO}_{2}+4 \mathrm{HF}=\mathrm{SiF}_{4}+2 \mathrm{H}_{2} \mathrm{O}$

$\mathrm{CaCO}_{3}+2 \mathrm{HF}=\mathrm{CaF}_{2}+\mathrm{H}_{2} \mathrm{O}+\mathrm{CO}_{2}$

Phosphate content estimated as $\mathrm{P}_{2} \mathrm{O}_{5}$ in deposit was observed to be range from 4.0$5.8 \%$ that might be due to excess dosing of phosphate in to the boiler WCR. It was found that phosphate treatment causes (Robin, 2004) excessive corrosive thinning ("wastage") on the steam generating tubes. Therefore many USA utilities (Robin, 2004) ceased phosphates dosing in boilers WCR and adopted an all volatile treatment (AVT) for secondary boiler water treatment.

Table III. The quantitative range of deposits $\left(\mathrm{gm}^{-2}\right)$ in boiler WWTs before chemical cleaning.

\begin{tabular}{l|c|c}
\hline Location & Insulation side & Fire side \\
\hline Back wall & $106-280$ & $180-370$ \\
Front wall & $71-230$ & $217-488$ \\
Right wall & $93-290$ & $210--378$ \\
Left wall & $108-240$ & $170-326$ \\
\hline
\end{tabular}

Table IV. Average concentration $\left(\mathrm{mgL}^{-1}\right)$ of ionic impurities removed in chemical solution and (\%) i mpurities removed at different stages of cleaning operation.

\begin{tabular}{l|c|c|c|c|c|c|c|c|c|c}
\hline \multicolumn{9}{c|}{ Ionic impurities, $\mathrm{mgL}^{-1}$} & \multicolumn{4}{|c}{ Impurities removed (\%) } \\
\hline CS & $\mathrm{C} \mathrm{Sol.M}^{3}$ & $\mathrm{pH}$ & $\mathrm{Fe}$ & $\mathrm{Cu}$ & $\mathrm{SiO}_{3}^{-2}$ & $\mathrm{PO}_{4}{ }^{3-}$ & $\mathrm{Fe}$ & $\mathrm{Cu}$ & $\mathrm{SiO}_{3}^{-2}$ & $\mathrm{PO}_{4}{ }^{3-}$ \\
FSAE & $60 \pm 0.5$ & NWR & 242 & 0.15 & 231 & 139 & 33.4 & 20 & 39.6 & 26.3 \\
SSAE & $60 \pm 0.5$ & NWR & 230 & Trace & 32 & 55 & 82.9 & Trace & 7.4 & 8.9 \\
\hline
\end{tabular}

CS- Cleaning stage. NWR - Not within range. C Sol - Cleaning solution.
Each etching stage hydrochloric acid was used for the removal of deposits containing phosphate, aluminum, calcium and magnesium etc., because of its batter performance in stagnant state. And while $0.5 \%$ urotropine was used as an inhibitor along with the cleaning solution to prevent corrosion on metallic surfaces for steel tube (carbon steel,st.-20,Russia) of boiler water wall. Washing agent 1\% OP-10 was employed for better action on water-surface system during cleaning operation. Average concentration of ionic impurities removed in each of the cleaning stages is shown in Table IV .After completion of TSAE operation, the inside surfaces of boiler WWTs were neutralized very carefully by ammonia solution (as per procedure) to avoid hydrogen damages during restart up of the unit for operation.

$$
\begin{aligned}
& 2 \mathrm{Fe}_{2} \mathrm{O}_{3}+12 \mathrm{HCl}=4 \mathrm{FeCl}_{3}+6 \mathrm{H}_{2} \mathrm{O} \\
& \mathrm{CaO}+2 \mathrm{HCl}=\mathrm{CaCl}_{2}+\mathrm{H}_{2} \mathrm{O} \\
& \mathrm{MgO}+2 \mathrm{HCl}=\mathrm{MgCl}_{2}+\mathrm{H}_{2} \mathrm{O} \\
& \mathrm{CuO}+2 \mathrm{HCI}=\mathrm{CuCl}_{2}+\mathrm{H}_{2} \mathrm{O}
\end{aligned}
$$

Deposit remains on the inside surface of boiler WWTs was (Table V) analyzed per- 
fectly after the completion of TSAE followed by passivating operation. Intimate analyses of the deposit revealed it contained maximum $63 \mathrm{gm}^{-2}$ (Table V) of deposit after cleaning operation followed by passivation. During passivation a dark black colored thin layer of ferrosoferic oxide (Table VI) was developed on internal surface of the tube, which was found protective against corrosion for three months kept in open atmosphere.

After completion of TSAE followed by passivation operation, the manholes of boiler bottom water walls headers were opened. Inspection revealed that no sludge, scale particles, weld flash were present. Overall results were attained satisfactory. Close macro-structural examinations (SEM image) of the boiler WWTs materials(after 96000h of operation) before TSAE operation revealed micro-pits and flow lines on the internal surfaces of the tube materials (Fig. 2 and Fig. 3). That's mirco-pits might be caused by oxygen corrosion due to traces of dissolved oxygen (DO) and while flow lines might be due to long time heat and steam flow through the steam generating tubes. Similar types of micro- pits were also observed on the boiler WWTs materials after TSAE operation (Fig. 4), but there no groove, gouge, micro-cracks etc. were observed. However, these micropits might be previously happened during operating period due to insufficient or interrupted dosing of hydrazine in the boiler feed water cycle or short of boiler preservation during start up or shut down of the unit.

However Table VI shows the avrage \% composition of deposits remained in boiler WWTs aftercleaning operation and passivation.

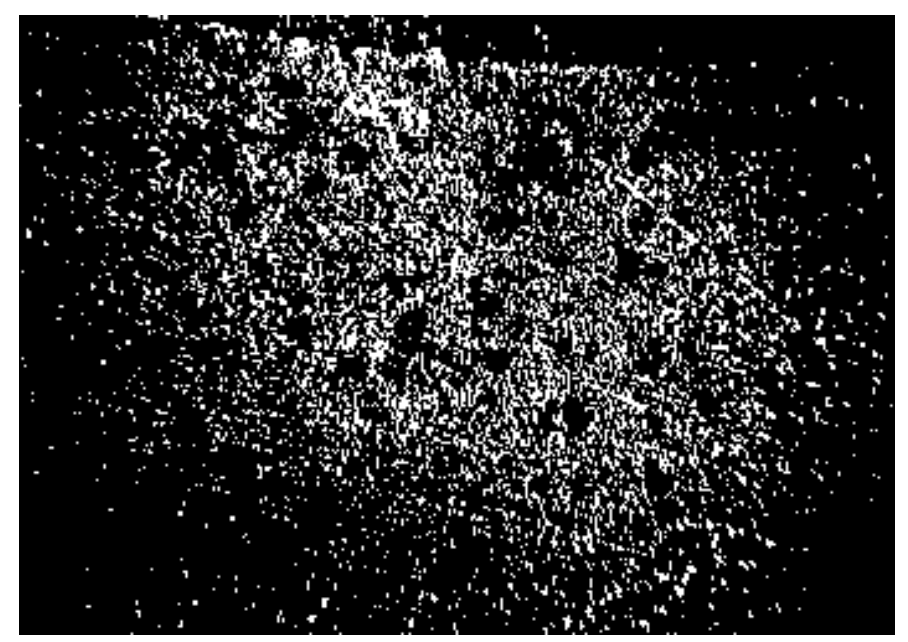

Fig. 2: SEM image of transverse section of $\varnothing 60 \times 6 \mathrm{~mm}$ carbon steel (st.-20, Russia) water wall tube, $x$ 60, showing pits before TSAE operation 


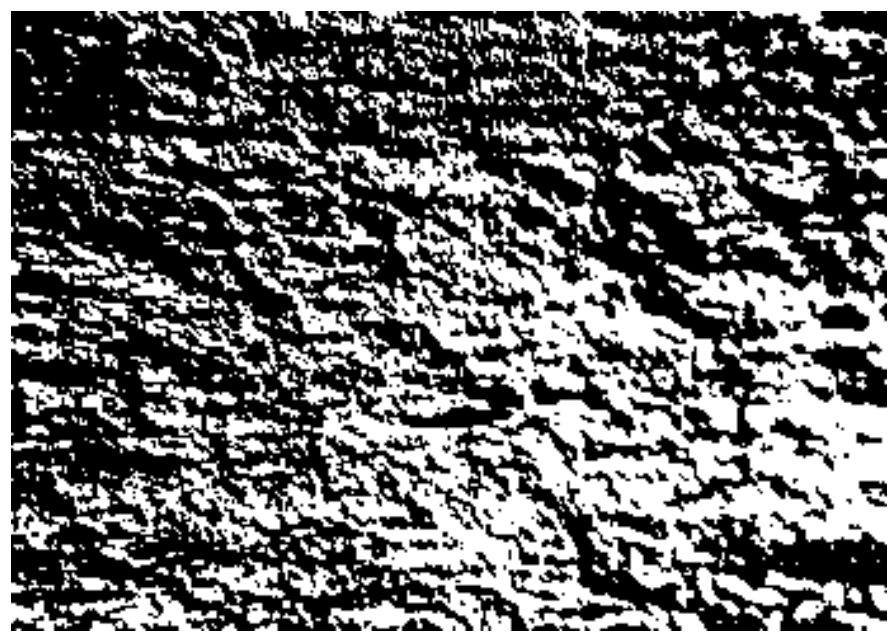

Fig. 3: SEM image of longitudinal section of $\emptyset 60 \times 6 \mathrm{~mm}$ carbon steel (st.-20, Russia) water wall tube, $x$ 60, showing flow lines before TSAE operation.

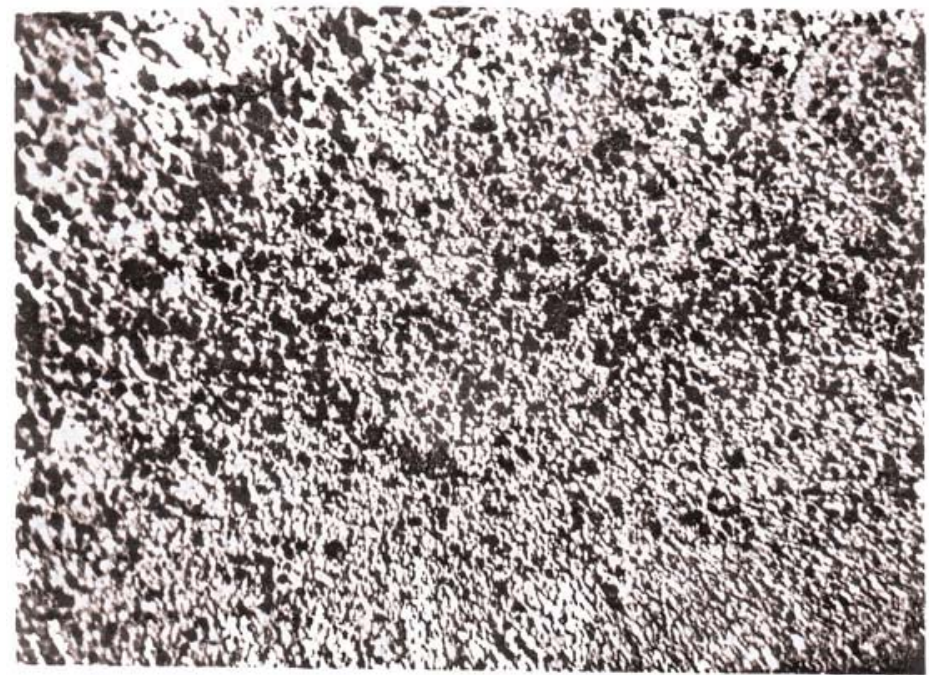

Fig. 4: SEM image of transverse section of $\varnothing 60 \times 6 \mathrm{~mm}$ carbon steel (st.-20, Russia) water wall tube, $x$ 60, showing pits after TSAE operation. 
Table V. Average quantity of residual deposits $\left(\mathrm{gm}^{-2}\right)$ that remained in boiler WWTs

\begin{tabular}{l|c}
\hline $\begin{array}{l}\text { After cleaning operation. } \\
\text { (identity of tubes) }\end{array}$ & Deposits (rub out method) \\
\hline Front water wall (fire side) & 45 \\
Left water wall (insulation side) & 50 \\
Rear water wall (fire side) & 51 \\
Back water wall (fire side) & 63 \\
\hline
\end{tabular}

Table VI. Average \% composition of deposits remained in boiler WWTs after cleaning operation and passivation.

\begin{tabular}{l|c|c|c|c|c|c|c}
\hline Constituents & $\mathrm{Fe}_{3} \mathrm{O}_{4}$ & $\mathrm{SiO}_{2}$ & $\mathrm{Al}_{2} \mathrm{O}_{3}$ & $\mathrm{CaO}$ & $\mathrm{MgO}$ & $\mathrm{P}_{2} \mathrm{O}_{5}$ & $\mathrm{CuO}$ \\
Average (\%) & 95.5 & 1.78 & 0.12 & 0.32 & 0.28 & 0.83 & Trace \\
\hline
\end{tabular}

\section{Conclusion}

From overall observation it has been concluded that not less than 90\%of impurities were removed by this newly set up TSAE technique. The cleaning efficiency of ammonium hydrogen fluoride in presence of hydrochloric acid, urotropine and OP-10 (cleaning agent, Russia) is found to be satisfactory. Passivation on cleaned surface of the boiler WWTs applying ammonia containing sodium nitrate solution was also found to be satisfactory.

\section{Acknowledgements}

The authors are acknowledges thanks to $\mathrm{M}$. Inna and A. Salvic, Chemical Experts of ENERGOREMONT, Kharkov, Ukraine-12, for their cooperation and Head, Department of Materials and Metallurgical Engineering
(MME), Bangladesh University of Engineering and Technology (BUET), Dhaka -1000,Bangladesh for macro-structural examinations.

\section{References}

Bodong L. Changzheng, Y. (1999) Application of citric acid cleaning process in boiler cleaning, Ниахие Qingxi, 15(6): 11-15(Ch).

Changming, L. (2000) Chemical cleaning agent for boiler superheaters, Cailiao Baohu, 33(10): 42-43(Ch).

Changzheng, Y. Yinggao, W. Zhengzun, X. Shunhe, Z. Xiaoming, Z. Daming, H. (1999) Chemical cleaning of boiler in Qinhuandao Power Plant, Ниахие Qingxi,15(5): 5-8 (Ch). 
Chemistry control of thermal power plants training materials. (1987) Thermal Power Development, TEPCO, JICA, Japan, 35.

French, M. (1981), Cleaning of boiler using hydrofluoric acid, Chem. and Ind., 389 .

Jeffery, G.H., Bassett, J., Mendham, J. Denney, R. C. (1989) Vogels Textbook of Quantitative Chemical Analysis, 5th End. London, 678-707.

Kostrikin, Y. (1967) Manual on analysis of water, steam and sediments at thermal power facilities, Energia (Russia), 3-270.

Operational Manual, GTPS, BPDB Bangladesh (1973).

Poulson, B. Robision, R. (1980 ) Study on stress corrosion cracking during acid cleaning operation , Corrosion Sci., 20(6): 687.

Robin, L.J. (2004). Mitigation corrosion problems in LWRs via chemistry changes, Power Plant Chemistry, 6(11): 665.

Sakurai, S., Masaharu, H., Hachiro, E., Makoto, Y., Hiroaki, N. Mimhihiro, K. (2000) Eur. Pat. Appl. EP 1,143037, .8.
Sohail, M.A. Mustafa, A.I. (2001) Acid cleaning operation for a natural circulation high pressure drum boiler unit of thermal power station, Indian J. Chem. Techol., (8): 223226.

Sohail, M.A. Mustafa, A.I. (2002) Hydrazine hydrate cleaning operation for a natural circulation high pressure drum boiler unit of thermal power station. Bang J Sci Res 24(2): 27-32.

Sohail, M.A., Bulavco, A. Kostikov, S. (1997) Chemical acid cleaning of water wall tubes for a natural circulation high pressure drum boiler unit of a thermal power station, $J$. Bang. Chem. Soc., 10 (1):1-7.

Sohail, M.A. Mustafa, A.I. (2006) Acid cleaning of impurities in natural circulation high pressure drum boiler, Malysian $J$. of Chemistry, 8 (1): 080-086.

Zhao, W. (1999) Alkali cleaning of small size boiler, Ниахие Qingxi, 15(1): 19-21 (Ch).

Zhaoying, D. (1999). Application of glycolic acid in chemical cleaning of a power plant boiler, Huахие Qingxi,15(1): 12-14(Ch).

Received : July 23, 2007;

Accepted : April 15, 2008. 